\title{
Effect of insect-mediated dispersal on the genetic structure of postglacial water mite populations
}

\author{
ANDREW J. BOHONAK† \\ Section of Ecology and Systematics, Corson Hall, Cornell University, Ithaca, NY 14853, U.S.A.
}

\begin{abstract}
Assaying population structure in species that differ in dispersal ability can help to determine whether population differentiation is dependent on the movement of individuals between populations. Here, allozyme variation is analysed in over 1100 individuals from nine species and two species complexes of Arrenurus water mites collected throughout north-eastern North America. As larvae, eight taxa are obligate parasites of winged adult insects that provide the primary opportunity for dispersal. Three additional species have lost the ability to parasitize insects and do not disperse in this manner. Consistent with the glaciated history of the region, very low allozyme heterozygosity was found in these taxa $\left(H_{\mathrm{o}}=0.00-0.12\right)$, near panmixia in five out of seven species for which population differentiation was calculated and no patterns of isolation by distance over spatial scales up to several hundred kilometres. Nonetheless, in two out of three comparisons between sister species with and without parasitic larvae, parasitism was significantly associated with higher heterozygosity. Population differentiation could also be contrasted for two of these sister species pairs; in each case, lower estimates of $F_{\mathrm{ST}}$ were found in the mites able to disperse on insects. The statistical significance of these contrasts was dependent on the method used to estimate variance. At the scale of the genus, behavioural differences among insect vectors allows for broader hypotheses that relate water mite genetic diversity to dispersal ability. For the genus, rank correlations of dispersal ability with direct count heterozygosity $(n=11)$ and population differentiation $(n=7)$ were not significantly different from zero. These results are consistent with the hypothesis that allozyme population structure is primarily the result of historical patterns in these regions. However, comparisons between sister species suggest a limited role for dispersal in homogenizing populations genetically, even when drift-gene flow equilibrium has not been achieved.
\end{abstract}

Keywords: Acari, allozymes, freshwater invertebrate, $F_{\mathrm{ST}}$, gene flow, population genetics.

\section{Introduction}

The relationships among dispersal, gene flow and genetic population differentiation have remained resistant to generalizations despite a continued accumulation of studies over the past three decades. The use of allozymes for population genetic studies has been particularly controversial. Although allozyme population differentiation is often used to make inferences regarding the movement of individuals, some have characterized allozyme differentiation as having little

Correspondence. E-mail: bohonak@hawaii.edu

$\dagger$ Present address: Center for Conservation Research and Training, 3050 Maile Way, Gilmore 409, University of Hawaii, Honolulu, Hawaii 96822, U.S.A. or nothing to do with ongoing gene flow, because of historical influences (e.g. Boileau et al., 1992; Bossart \& Prowell, 1998) or pervasive natural selection (Karl \& Avise, 1992). One way to separate these factors is to assay loci that are likely to evolve at different rates and under different selective regimes (e.g. Burton \& Lee, 1994). An alternative is to determine the relative effects of factors such as history, natural selection and driftgene flow balance using comparative studies focused on multiple species. For example, geographical patterns in mtDNA lineages show a common break between Atlantic and Gulf Coast populations on the east coast of North America in many taxa, concordant with the geological history of the region (Avise, 1992). Other comparative studies have focused on species that differ in dispersal ability, and these have found that species 
with greater dispersal abilities generally show less population differentiation than species with restricted dispersal (e.g. Waples, 1987; reviewed by Bohonak, 1999).

Comparative tests of hypotheses that link dispersal ability to genetic differentiation have often concentrated on marine species differing in larval development and planktonic duration, because species with planktotrophic larvae are hypothesized to disperse further than species with nonplanktotrophic larvae (see Hedgecock, 1986; Palumbi, 1995). However, studies comparing genetic population structure in nonmarine species that differ in dispersal potential often include distantly related taxa. This can bias the results of comparative studies towards the conclusion that ongoing dispersal is unrelated to population structure. As differences in phylogenetic history, ecology and biogeography increase, confounding factors will increasingly weaken correlations and muddle interpretation of the results. The ideal model system would include multiple sympatric sister species differing only in their ability to disperse, and these types of taxa will provide the strongest evaluation of the relationship between dispersal and population differentiation.

Organisms living in recently glaciated areas of North America provide a particularly demanding system in which to test correlations between dispersal, gene flow and population differentiation. Freshwater invertebrates in this region have been characterized as being far from equilibrium because of extreme founder events and recent glaciation (e.g. Hebert \& Hann, 1986), and allozyme-based gene flow estimates in these animals seem to bear no relationship to the amount of dispersal that is occurring (Boileau et al., 1992). However, the conclusions drawn by Boileau et al. (1992) were based on comparisons between species from different classes and phyla. Here, the relationship between dispersal and population differentiation in north-eastern North America has been assessed for a group of freshwater invertebrates more taxonomically restricted than those studied to date. Larvae of water mites from the genus Arrenurus use a variety of adult insects as parasitic hosts, and these insects provide the primary means of dispersal. This study examines how the loss of parasitism in three Arrenurus lineages has impacted population differentiation. In addition, the relationship between host use and patterns of genetic variation has been investigated in this genus. As a model system, water mites provide a unique opportunity to test the degree to which population differentiation actually reflects the ongoing dispersal of individuals in a landscape far from a drift-gene flow equilibrium.

\section{Materials and methods}

\section{Life history of Arrenurus water mites}

Nearly all species of water mite larvae (Acari: Hydrachnida) are obligate ectoparasites on aquatic insects (Smith \& Cook, 1991). After hatching from eggs, mite larvae seek out insect larvae and pupae. As the insects emerge, the mites attach to the winged adult and begin to feed. When their hosts later return to water to mate or oviposit, the engorged mites release and fall to the pond, lake or stream bottom. In most genera, the adult portion of the life cycle is then spent in a free-living state. Reproduction is sexual. Thus, the mites disperse parasitically only once in their lives, although dispersal presumably occurs by other unknown means on rare occasions. Water mites in the genus Arrenurus parasitize nematoceran flies (e.g. tanypodine midges, chaoborids and mosquitoes) or odonates (libellulid dragonflies and damselflies), and individual species of mites are faithful to only one of these insect taxa nearly $100 \%$ of the time (Stechmann, 1978).

In contrast to the generalized life cycle, three species of Arrenurus have independently lost the ability to parasitize insects (two in subgenus Truncaturus and one in subgenus Megaluracarus). Eggs of these species hatch directly into a postlarval stage that possesses no means of parasitic dispersal, analogous to the direct-developing life history found in some marine invertebrates. This life cycle has evolved independently over 20 times in at least 14 genera (Smith, 1998).

\section{Collection of mites}

From 1994 to 1996, water mites were collected using standard techniques (see Smith \& Cook, 1991) from sites throughout New York State and Ontario, Canada (Fig. 1). An attempt was made to sample as many individuals in the genus Arrenurus as possible from a diversity of bogs, ponds, seepage areas, lakes and slow rivers. Although most of the species were sampled in habitats small enough to support only a single population, it seemed probable that separate bays of large lakes and rivers contain multiple populations of the same species. In order to minimize sampling artifacts imposed by habitat size, collections in large lakes and rivers were restricted to areas of $\approx 200 \mathrm{~m}^{2}$ or less.

Sample sizes for nine species and two species complexes were large enough for analyses of heterozygosity and population differentiation (see below). Within these taxa, geographical distances between pairs of populations ranged between $300 \mathrm{~m}$ and $385 \mathrm{~km}$, and the mean pairwise distance ranged between $56 \mathrm{~km}$ (for A. rufopyriformis) and $189 \mathrm{~km}$ (for A. danbyensis). 


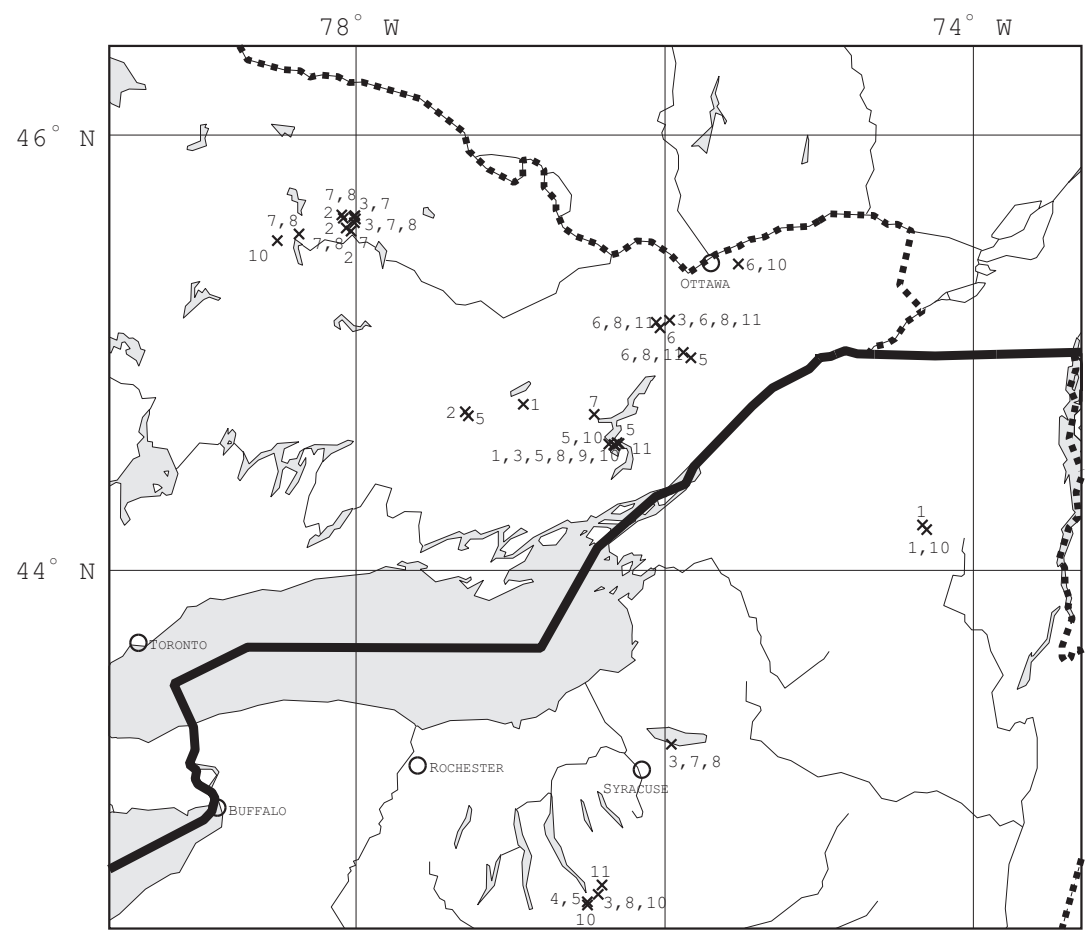

Fig. 1 Collection sites. Taxa are numbered as in Table 1.

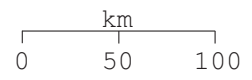

For most of the Arrenurus species in this study, sampling occurred in populations near the limits of a broad geographical range (Crowell, 1961; Mullen, 1974; B. Smith and I. Smith, pers. comm.). Arrenurus manubriator, A. birgei, A. danbyensis and A. planus are found throughout most of eastern North America, ranging from Ontario to the Gulf coast. The distributions of $A$. angustilimbatus and the A. mamillanus/neomamillanus and $A$. kenki/palustris species complexes overlap with these four species in Ontario and New York and stretch north into Manitoba and Quebec. Arrenurus apetiolatus is found throughout both North America and South America. The presumed midge parasite $A . n$. sp., nr. manubriator has been found in sites in the north-eastern United States, eastern Canada, North Carolina and the south-central United States and seems to possess a distribution that circumscribes its directly developing sister species A. manubriator with little geographical overlap (B. Smith, pers. comm.). Similarly, populations of the direct developer $A$. rufopyriformis are restricted to three centres that are surrounded by populations of $A$. angustilimbatus (five known populations near Ottawa, Ontario, a single population in New Jersey and several populations in Michigan). For logistical reasons and because of the possibility that $A$. rufopyriformis in these three areas do not represent a monophyletic taxon, the
A. rufopyriformis populations outside of Ontario were not included in the study. Only a single population of the direct developer $A$. $n$. sp., nr. danbyensis is known.

\section{Electrophoresis}

Individual adult mites were identified with published keys (Cook, 1954a,b, 1955; Mullen, 1976), verified by B. Smith (Ithaca College, NY, USA) and stored live at $8^{\circ} \mathrm{C}$ for periods of time that ranged from several weeks to more than a year. To promote metabolic activity, mites were warmed to room temperature and fed ostracods (their natural food) for 2 days before electrophoresis. Individuals kept in the laboratory for extended periods of time produced electrophoretic patterns that did not appear to differ from recently collected individuals.

Nine isozymes representing 15 putative loci were screened using a cellulose acetate system (protocols and stains modified from Hebert \& Beaton, 1993). Five isozymes were run in a Tris/glycine (TG) buffer: ADH (EC 1.1.1.1), ARK (2.7.3.3), FUM, two loci (4.2.1.2), GPI, two loci (5.3.1.9) and PGM, two loci (5.4.2.2). Four isozymes were run in a citric acid/aminopropylmorpholine (CAAPM) buffer system: AAT, three loci (EC 2.6.1.1), G3PDH (1.2.1.12), MDH, two loci (1.1.1.37) and 6PGDH (1.1.1.44). Individual mites were

(C) The Genetical Society of Great Britain, Heredity, 82, 451-461. 
typically large enough to permit staining for $12-15$ gels. In all cases, heterozygotes stained according to known quaternary structure. Marker alleles consisting of Daphnia from a clonal laboratory line were run in two lanes on every gel.

Twenty-six taxa were collected from 50 sites. From this data set, over 1100 individuals from 11 taxa in which 10 or more individuals had been sampled were analysed. These taxa included two species complexes for which taxonomy is unreliable and in which a number of cryptic species are thought to be present (A. kenki) palustris spp. and A. mamillanus/neomamillanus spp.). Two currently undescribed species were also included in the study (A. n. sp., nr. manubriator and $A$. $n$. sp., nr. danbyensis). Although no published phylogeny is currently available for the genus Arrenurus, traditional subgeneric affiliations and recently recognized sister species are presented in Table 1.

\section{Estimation of heterozygosity, population differentiation and gene flow}

Observed (direct count) heterozygosities averaged across individuals and loci $\left(H_{\mathrm{o}}\right)$ were calculated in each of the 11 taxa. Because of unequal sample sizes among populations, heterozygosity was also calculated by averaging across (sub)populations $\left(H_{\mathrm{o}}[\mathrm{s}]\right)$.

Population differentiation was estimated using $F$-statistics in seven species that were collected from more than one population. (Because species could not be separated reliably in the A. mamillanus/neomamillanus and A. kenki/ palustris species complexes, population differentiation was not quantified in these taxa.) Mean squares for the calculation of $f_{\mathrm{IS}}, F_{\mathrm{IT}}$ and Weir and Cockerham's $\theta$ (an estimator of $F_{\mathrm{ST}}$ ) were obtained by using indicator variables for each allele and generating nested analysis of variance tables for each allele at each locus (Weir, 1990). Variance estimates for the $F$-statistics were determined by jackknifing across alleles and from 500 bootstraps conducted across loci for each species (Weir, 1990).

The relationship between $\theta$ and $\log$ (geographical distance) was examined for all pairwise combinations of populations in the seven species for which an overall $\theta$ was calculated (Slatkin, 1994). No isolation by distance was detected over the scale for which populations were sampled. Accordingly, an island model estimate of $F_{\mathrm{ST}}$ was assumed to be an appropriate descriptor of population differentiation, and gene flow was estimated as $\mathrm{Nm}$, the number of migrants per generation, using the relationship $N m=[(1 / \theta)-1] / 4$.

\section{Correlations with loss of parasitism}

Host type (or the absence of parasitism) is expected to remain constant over the evolutionary lifetime of each mite species, because it is phylogenetically conservative within the genus Arrenurus and across other mite genera (see above). Thus, if host use can be reliably and categorically ranked from low to high dispersal ability, it should provide an accurate, qualitative metric of dispersal. If the ranking is truly categorical, it is a long-term estimate not subject to extreme fluctuations in any particular generation. Because of this, clear life history differences related to dispersal ability often correlate well with long-term averages of population differentiation such as $F_{\mathrm{ST}}$ (Bohonak, 1999).

Table 1 Subgeneric affiliations of Arrenurus water mites in this study (Cook, 1954a,b, 1955; Mullen, 1976), number of individuals and number of populations surveyed

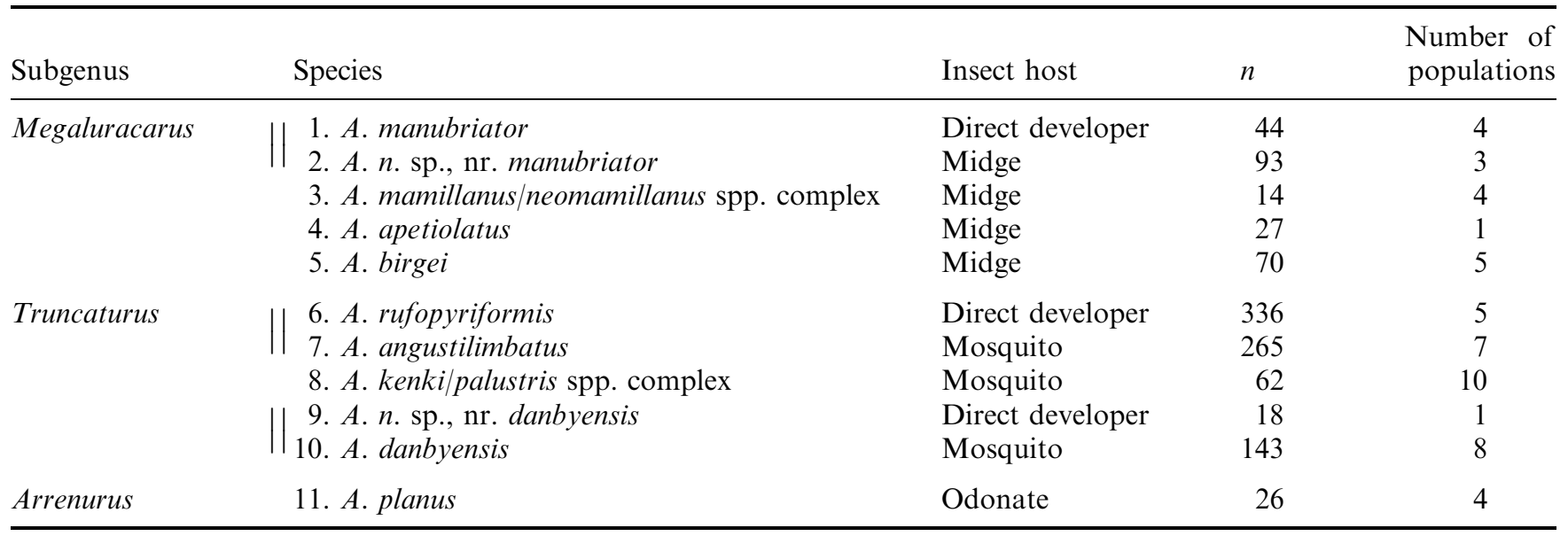

Hypothesized sister species (1-2, 6-7 and 9-10) are bracketed by double lines (Smith, 1998; unpubl. data). Direct developers are those species that have lost the ability to parasitize insects. Arrenurus rufopyriformis is synonymous with A. lacrimatus Cook (see Mullen, 1974, 1976). 
It was assumed that nonparasitic species disperse less than their parasitic sister species. Water mite adults are obligately aquatic, and species that forgo parasitism can only disperse on rare occasions arising from chance events (e.g. wind, birds). If habitats such as lakes and rivers are large enough to include multiple populations of the same species, it is possible that adults may also disperse by swimming. However, both parasitic and nonparasitic adults should disperse equally well via birds, mammals or swimming.

It was assumed that population differentiation would be greater in species that have lost the ability to parasitize insects. This was tested by comparing $\theta$ between the sister species $A$. manubriator and $A$. $n$. sp., nr. manubriator, and between the sister species A. rufopyriformis and A. angustilimbatus. Statistical significance was tested by comparing $95 \%$ confidence intervals obtained by jackknifing and by bootstrapping over loci.

Heterozygosity is also expected to depend on dispersal ability, with parasitic species possessing higher observed heterozygosity. This is because gene flow between populations should increase effective population size and slow the rate of drift. (In the absence of gene flow and new mutations, populations will eventually lose all variation; conversely, effective population size will be maximal when gene flow is so high as to preclude population subdivision.) Three sister species pairs can be contrasted for heterozygosity (Table 1). Because electrophoretic variation is higher for some loci across all species (see Table 2), statistical significance for the contrasts was determined by comparing species on a locus-by-locus basis using a one-sided, two-sample sign test.

\section{Correlations with host type}

Variation in host type permits a more generalized hypothesis relating dispersal ability to population genetic metrics. Parasitic species of water mites tend to be highly specific to particular insect taxa; however, only one mite studied here (A. danbyensis, subgenus Truncaturus) is restricted to a single host species of insect (the mosquito Coquilletidia perturbans). Other Truncaturus mites are more opportunistic, parasitizing multiple mosquito species as available. Similarly, the remainder of the mites are found on many insect species within the same higher taxon (Smith \& Oliver, 1986; Smith \& Cook, 1991). Phylogenetic patterns of host use are relatively conservative, with nearly all mosquito parasites restricted to the subgenus Truncaturus, midge parasitism found primarily in the subgenera Megaluracarus and Micruacarus and odonate parasitism found only in the subgenus Arrenurus. As a result of this host specificity, an attempt was made to rank dispersal ability in each mite species based on the subfamily, family or order of its insect host. [Because dispersal in $C$. perturbans seems to be typical of mosquitoes in northeastern North America (e.g. Johnson, 1969), no distinction in dispersal ability was made between $A$. danbyensis and the other mosquito parasites.]

A review was made of the available literature on dispersal in the taxa parasitized by Arrenurus mites in

Table 2 Observed heterozygosity averaged by individual $\left(H_{\mathrm{o}}\right)$ for each locus with more than one allele

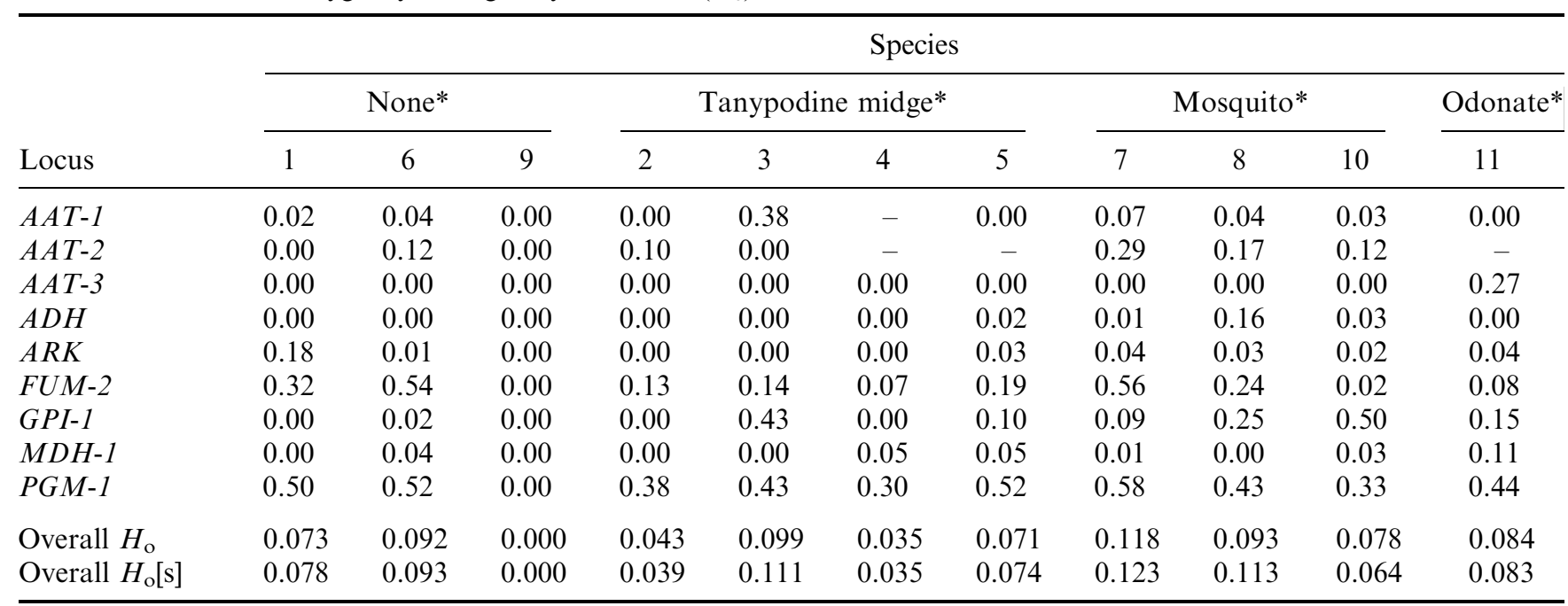

*Dispersal vector.

Averages over loci are presented for $H_{\mathrm{o}}$ and for observed heterozygosity averaged at subpopulation level $\left(H_{\mathrm{o}}[\mathrm{s}]\right)$. Species numbers are the same as in Table 1.

(C) The Genetical Society of Great Britain, Heredity, 82, 451-461. 
North America. Of these taxa, odonates (damselflies and libellulid dragonflies) seemed to possess the most variability, with continental migrations being reported for some species and high degrees of territoriality in others. However, even in odonates that possess territorial males, males forage away from their territory, and both sexes disperse during the teneral phase before territory acquisition (Corbet, 1980). For example, Cook (1991) recaptured only $22 \%$ of marked teneral males in the territorial Leucorrhinia frigida (an Arrenurus host), in contrast to $61 \%$ of mature males $(0 \%$ of teneral and $0.6 \%$ of adult females were recaptured). Overall, odonates were judged as likely to disperse mites more often and further than the other insect taxa, with single odonates often carrying hundreds of mites and dispersing over tens or hundreds of kilometres (e.g. Mitchell, 1959, 1962, 1965; Johnson, 1969; Cook, 1991; Miyakawa, 1994). Dispersal in mosquitoes has been studied more extensively. In contrast to odonates, the mosquito species used by Arrenurus are less heavily parasitized (typically 1-11 mites) and tend to disperse $10 \mathrm{~km}$ or less (e.g. Johnson, 1969; Jalil \& Mitchell, 1972; Mullen, 1974; Brust, 1980; Service, 1993; Jensen \& Washino, 1994). The dispersal literature on midges is exceedingly small; nonetheless, it was hypothesized that tanypodine midges disperse fewer mites for shorter distances than either mosquitoes or odonates. Dispersal distances for tanypodine midges are typically $<100 \mathrm{~m}$ from the site of emergence, and less than five mites are usually found per host (e.g. Efford, 1963; Booth \& Learner, 1978; Lanciani, 1978; LeSage \& Harrison, 1980; Kouwets \& Davids, 1984; Jackson \& Resh, 1989). Thus, nonparasitic species, midge parasites, mosquito parasites and odonate parasites were assigned dispersal ranks of $1,2,3$ and 4, respectively. Although numerous other ecological and demographic differences between the mites undoubtedly exist, the restriction of this study to a single genus provides some assurance that the species studied were as biologically similar as possible.

Spearman rank correlations of the dispersal ranking with $F_{\mathrm{ST}}, H_{\mathrm{o}}$ and $H_{\mathrm{o}}[\mathrm{s}]$ were used to assess whether dispersal was related to genetic variation at the level of the genus. Significance values for one-tailed tests were obtained from Daniel (1987).

\section{Results}

Of the 15 loci scored, six were monomorphic within all species (FUM-1, GPI-2, G3PDH, MDH-2, PGM-2 and $6 P G D H)$. The remaining nine were assayed in all taxa with the exception of $A A T-1$ and $A A T-2$, for which staining was problematic in smaller individuals. Allozyme variation in Arrenurus was very low, with average heterozygosities across 15 loci ranging from 0.12 in
A. angustilimbatus to 0.00 in $A$. $n$. sp., nr. danbyensis (Table 2). A high degree of variation existed among loci and, although $P G M-1$ and $F U M-2$ tended to display the highest heterozygosities, no other patterns were apparent.

Tests for departure from Hardy-Weinberg equilibrium were conducted on all locus-population combinations for which more than one allele was present, excluding the two complexes of cryptic species. Seventeen out of 138 tests were significant at $\alpha=0.05$. (After Bonferroni correction for multiple tests, only 10 departed significantly from Hardy-Weinberg.) In many of these cases, rare alleles and small to moderate sample sizes led to expected genotype frequencies less than 1 . When rare alleles were pooled, seven tests remained significant. Estimates of the inbreeding coefficient $f_{\text {IS }}$ were low in all taxa, with the exception of $A$. birgei, in which $f_{\text {IS }}=0.16$ (Table 3 ). The high $f_{\text {IS }}$ in $A$. birgei was caused by the presence of one individual in each of two populations that was homozygous for alleles that were rare in that population. The loci involved were $A D H$ and GPI- 1 in each case. Because the mites were collected at a time of year after dispersal but before breeding, these individuals were likely to be immigrants. When these animals were eliminated from the analysis, $f_{\text {IS }}$ dropped to 0.02 , but population differentiation remained high $(\theta=0.20)$.

Population differentiation was almost nonexistent in five of the seven species for which $F$-statistics were calculated (Table 3). However, four species possessed $\theta$ values significantly greater than zero (based on jackknifed $95 \%$ confidence intervals). Estimates of $\theta$ were slightly negative in $A$. $n$. sp., nr. manubriator, but the departure from zero was small and nonsignificant. Population differentiation in $A$. birgei and A. planus was large in comparison with the five remaining species, although variances were also highest in these two species. Assuming equilibrium and an island model of dispersal, gene flow estimates were high in all species $(\mathrm{Nm}=0.6$ or more individuals per generation; Table 3).

\section{Correlations with loss of parasitism}

Two comparisons of population differentiation between sister species possessing and lacking parasitism were possible. For each of these comparisons (A.n. sp., nr. manubriator vs. A. manubriator and $A$. angustilimbatus vs. A. rufopyriformis), the species lacking a means of larval dispersal possessed higher estimates of $\theta$ and lower estimated gene flow than species that parasitize insects (Table 4). Estimates of $\theta$ in A. angustilimbatus were approximately one-third of those in A. rufopyriformis and significantly lower according to jackknifed 


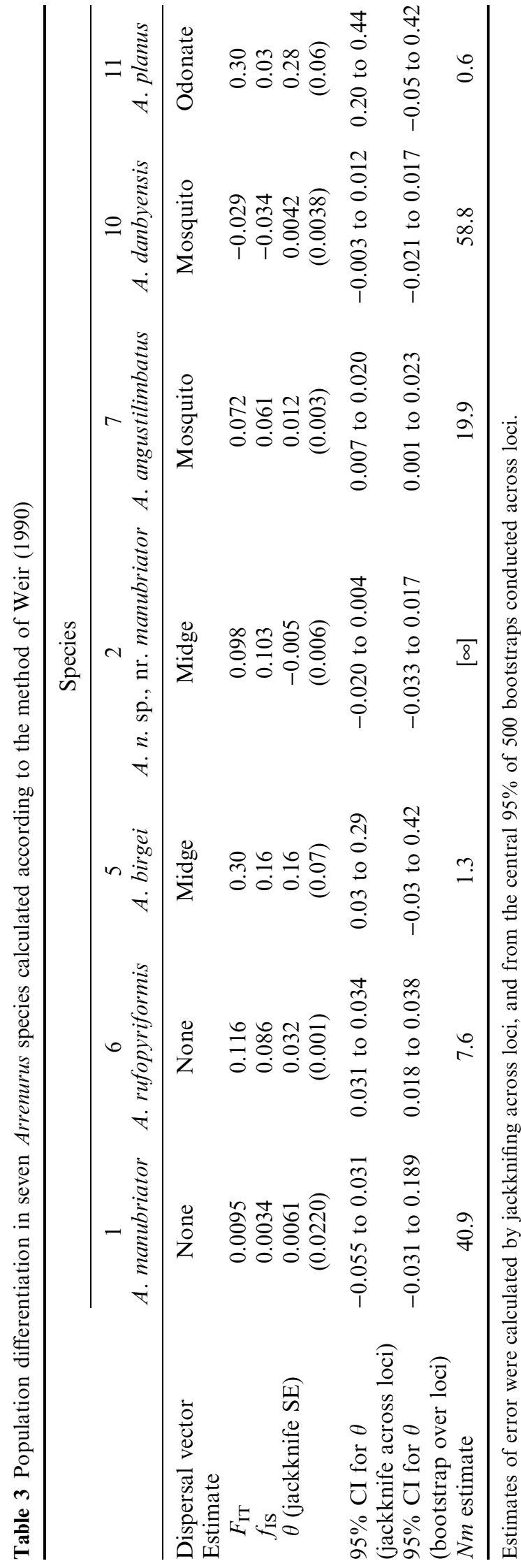

estimates of variance $(P<0.05)$. (For variance estimates bootstrapped across loci, the contrast was not significant; $0.05<P<0.10$.) The differences in population differentiation between A. manubriator and A. n. sp., nr. manubriator were not significant $(P>0.10$ for both jackknifed and bootstrapped estimates of variance).

In two of the three sister species contrasts, directdeveloping species possessed significantly less allozyme heterozygosity than their parasitic counterparts $(P=0.04, P=0.004$; Table 4). However, A. manubriator possessed more heterozygosity than $A$. n. sp., nr. manubriator, contrary to expectations.

\section{Correlations with host type}

There was some indication that heterozygosity increased across the four dispersal categories, with widely dispersing species tending to possess higher average heterozygosities than poorly dispersing species (Fig. 2). However, a high degree of variation existed within each dispersal category, and the odonate parasite thought to possess the highest dispersal ability ( $A$. planus) displayed only moderate levels of heterozygosity. The rank correlation of $H_{\mathrm{o}}$ with dispersal ability was not significant $\left(r_{\mathrm{s}}=0.45 ; \quad 0.05<P<0.10 ; \quad r_{\mathrm{s}}\right.$ for $H_{\mathrm{o}}[\mathrm{s}]=0.38$, $P>0.10)$. There was also no relationship between population differentiation and dispersal ability $\left(r_{\mathrm{s}}=-0.24, P>0.10\right.$; Fig. 3).

\section{Discussion}

Loss of parasitism in Arrenurus was only weakly associated with population genetic metrics in this study. Contrasts between sister species showed a slight increase in $\theta$ when parasitic dispersal was not possible, but interpretation of the results is complicated by near panmixia in five of the seven species for which $\theta$ was measured. In two out of three cases, the loss of parasitism was also associated with significant reductions in heterozygosity.

Relationships between allozyme variation and inferred dispersal ability were not apparent at the level of the genus. Across 11 species and species complexes of Arrenurus water mites, heterozygosity was not significantly correlated with dispersal tendency, despite the fixation of all 15 loci in one of the nondispersing species (A. n. sp., nr. danbyensis). Independent contrasts between Arrenurus taxa at higher phylogenetic levels (e.g. subgenera) would be more appropriate than using all 11 species as independent data points; however, many relationships among Arrenurus species are unknown at this time. Isolation by distance was not detected in seven species collected from multiple popu- 
Table 4 Comparison of $H_{\mathrm{o}}$ and $\theta$ between sister species with parasitic and direct-developing life cycles

Contrast

Heterozygosity

Parasitic species-direct developer

Population differentiation

Direction Sign test

A. n. sp., nr. manubriator (2)-A. manubriator (1)

$A$. angustilimbatus (7)-A. rufopyriformis (6)

$2<1$

$2<1 \quad P=0.97$

A. danbyensis (10)-A. n. sp., nr. danbyensis (9)

$7<6 * \quad 7>6 \quad P=0.04$

$10>9 \quad P=0.004$

Contrasts in bold are consistent with a priori expectations.

* $\theta$ is significantly $(\alpha=0.05)$ higher in $A$. angustilimbatus than in A. rufopyriformis when variance is calculated by jackknifing over loci, but not when bootstrapping (see Table 3 ).

lations (see Materials and methods), which may suggest strong founder effects or that long-distance dispersal is common. Furthermore, populations of five species were essentially panmictic across geographical scales up to several hundred kilometres, with $\theta$ values of 0.032 or less.

Boileau et al. (1992) studied allozyme population structure in Canadian populations of freshwater invertebrates, although water mites were not included in their survey. They concluded that dispersal is not related to population differentiation in this region of North America by comparing 15 species of Turbellaria, Anostraca, Cladocera, Copepoda, Ostracoda and Collembola. Despite a more restricted taxonomic focus in this study, the conclusions are generally similar, with one notable exception. The average estimate of $F_{\mathrm{ST}}$ in the taxa studied by Boileau et al. (1992) was 0.12, and all values were significantly greater than zero. Boileau et al. (1992) interpreted the lack of fit between gene flow

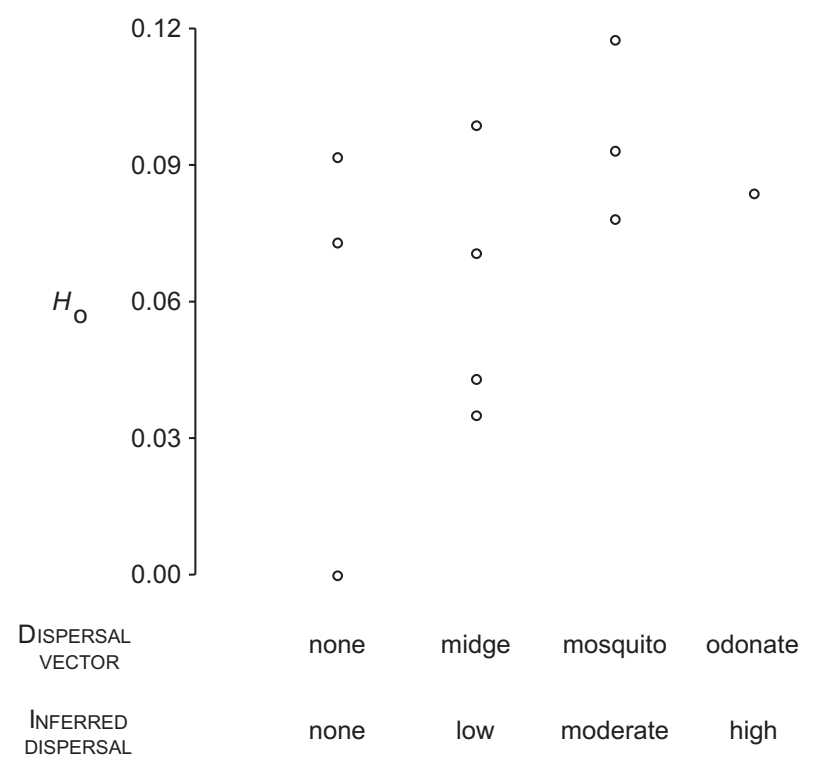

Fig. 2 Average observed heterozygosity as a function of dispersal vector in Arrenurus. estimates and dispersal (as inferred from morphological and behavioural characters) as being the result of pronounced founder effects, which led to an initial state of high population differentiation. In contrast, the water mites studied here more often possess estimates of $F_{\mathrm{ST}}$ that seem extraordinarily low.

Why would extreme departures from equilibrium lead to such different results? One possibility is that species from each study differ in the ways that they colonize new populations. For most of the taxa considered by Boileau et al. (1992), dispersal is infrequent and temporally variable, and populations are likely to be founded by one or only a few individuals. Population sizes can quickly reach $10^{5}-10^{8}$ individuals, particularly in asexual or parthenogenetic freshwater invertebrates such as the crustacean Daphnia. These conditions are likely to

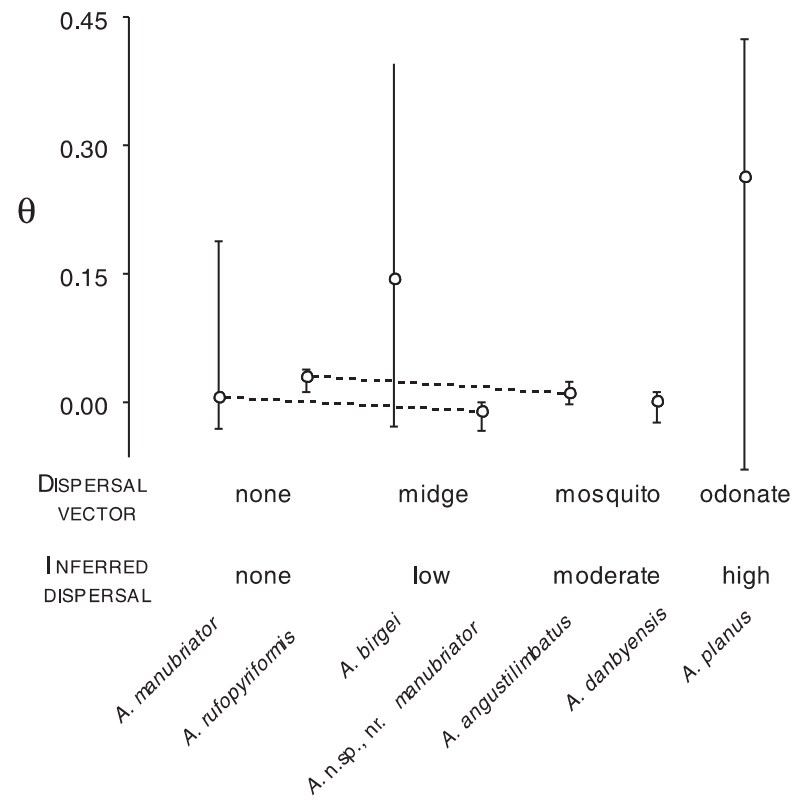

Fig. 3 Estimates of population differentiation $(\theta)$ as a function of dispersal vector. Dashed lines connect closely related sister species (see Table 1). Error bars are 95\% confidence intervals from bootstraps conducted across loci. 
promote marked founder effects and create high initial values of $F_{\mathrm{ST}}$.

In contrast, water mites are obligately sexual and disperse as juveniles rather than propagules resistant to drying. Dispersal via insect hosts may also be less variable from generation to generation than the unknown vectors that move most freshwater invertebrates. More importantly, the frequent existence of multiple mite larvae on each dispersing insect (e.g. Efford, 1963; Mitchell, 1965) means that new populations of many species would be colonized by multiple individuals. The size of founding populations could also be enhanced by the simultaneous dispersal of many winged insects by meteorological events (e.g. Mitchell, 1962). Thus, range expansions of mosquitoes, midges and odonates from glacial refugia at the end of the Pleistocene would be more likely to lead to genetically homogeneous populations of water mites with $F_{\mathrm{ST}}$ values close to zero than to high initial population differentiation. Because of this, separating the population genetic consequences of dispersal ability and population history in this system will require more rapidly evolving markers than allozymes. Even when sister species with divergent life histories can be collected in large numbers (such as $A$. rufopyriformis and $A$. angustilimbatus), it is statistically difficult to test the comparative hypothesis that $F_{\mathrm{ST}}$ estimates of 0.01 and 0.03 are different.

The only other study to date on allozyme differentiation in water mites provides support for the hypothesis that most of the Arrenurus species in this study are not in equilibrium. Edwards \& Dimock (1997) estimated $F_{\mathrm{ST}}$ as 0.12 for four populations of the midge parasite Unionicola formosa in North Carolina and 0.31 for six populations of $U$. foili throughout the south-eastern United States. Because freshwater habitats in North Carolina are likely to be older than those in New York and Ontario, it is notable that population differentiation is higher for both Unionicola species than for the midge parasite $A$. $n$. sp., nr. manubriator in this study. However, both the geographical scale of sampling and the $F_{\mathrm{ST}}$ estimate of 0.16 for the midge parasite $A$. birgei are intermediate between the two Unionicola species. These data are consistent with the hypothesis that the two Arrenurus species with relatively high amounts of population differentiation ( $A$. birgei and A. planus) are closer to a drift-gene flow equilibrium than those with very low amounts of differentiation. A study of latitudinal patterns of differentiation in widespread species would help to corroborate or refute this hypothesis.

Several alternative interpretations are also possible. The Arrenurus species might not be ecologically and demographically comparable with $U$. formosa or $U$. foili and may be much closer to equilibrium than the invertebrates studied by Boileau et al. (1992). The populations in this study are further south than those sampled by Boileau et al. (1992) and, as a result, the mites may have had considerably more time to reach an equilibrium between drift and gene flow. The ponds of Boileau et al. (1992) are thought to have been created by glacial rebound approximately 3000 years ago. In contrast, glacial influences in south-central Ontario lasted until the end of the Wisconsin glaciation (14 000-10 000 years BP), and invasions of most freshwater fish from refugia occurred between 12000 and 9000 years BP (Mandrak \& Crossman, 1992). Although some of the lakes, bogs and ponds from this region are likely to have been created by more recent geological and human activities, many are considerably older than 3000 years. In this case, near-zero values of $\theta$ would reflect high gene flow between bodies of water that are closely spaced relative to dispersal potential.

However, several lines of evidence suggest that patterns of allozyme variation are primarily a result of historical factors. First, isolation by distance was not evident in any species over geographical scales ranging between hundreds of metres and hundreds of kilometres. Secondly, the poor fit of host type with gene flow is inconsistent with an equilibrium interpretation, unless host type is not a good indicator of dispersal ability. An analysis of population structure that uses a larger geographical scale and additional species will be necessary for more detailed inferences. In addition, further ecological and genetic studies will be needed to reconcile gene flow estimates of 41 and seven individuals per generation in the nonparasitic, direct-developing species A. manubriator and A. rufopyriformis with the assumption that these mites possess no means of active dispersal.

Before approaching an equilibrium between drift and gene flow, gene frequencies can assume patchy distributions, clinal patterns of variation or more complicated mosaics (e.g. Nürnberger \& Harrison, 1995). For these reasons, the interplay between gene flow, random drift, history and natural selection on one (or many) loci usually leads to a number of equally plausible interpretations for any individual species. Studies of phylogenetically and ecologically comparable groups of species can be useful in discriminating among these alternatives. Although variation in the relatedness among organisms is typically regarded as a confounding factor in evolutionary studies, exploiting these relationships is one way to determine the relative impacts of history and contemporary gene flow on population structure. The results of this study verify that, in regions where historical effects are pronounced, a synthetic approach is most informative when focused at the lowest taxonomic level. Studies on closely related, yet ecologically 
divergent, species will provide the greatest insight for these types of systems.

\section{Acknowledgements}

I thank Bruce Smith for his advice and expertise in all things mitey. Carla Cáceres, Neil Davies, Sam Flaxman, Corey Freeman-Gallant, Neera Garga, Nelson Hairston, Jr, Richard Harrison, Cami Holtmeier, Amy Martin and Ian Smith provided commentary on earlier versions of this manuscript and field and laboratory assistance. The Freeman Adirondack Station, Ontario Ministry of Natural Resources, Queen's University Biology Station and the Wildlife Research Station in Algonquin Provincial Park provided accommodation and access to field sites. This project was funded by the Kieckhefer Adirondack fund and the National Science Foundation (DEB-9423603 and a training grant to Cornell University's Center for Applied Mathematics and Department of Ecology and Systematics).

\section{References}

AVISE, J. C. 1992. Molecular population structure and the biogeographic history of a regional fauna: a case history with lessons for conservation biology. Oikos, 63, 62-76.

BOHONAK, А. J. 1999. Dispersal, gene flow and population structure. Q. Rev. Biol., 74, 21-45

BOILEAU, M. G., HEBERT, P. D. N. AND SCHWARTZ, S. S. 1992. Nonequilibrium gene frequency divergence: persistent founder effects in natural populations. J. Evol. Biol., 5, 25-39.

BOOTH, J. P. AND LEARNER, M. A. 1978. The parasitism of chironomid midges (Diptera) by water-mite larvae (Hydracarina: Acari) in a eutrophic reservoir in South Wales. Arch. Hydrobiol., 84, 1-28.

BOSSART, J. L. AND PROWELl, D. P. 1998. Genetic estimates of population structure and gene flow: limitations, lessons and new directions. Trends Ecol. Evol., 13, 202-206.

BRUST, R. A. 1980. Dispersal behavior of adult Aedes sticticus and Aedes vexans (Diptera: Culicidae) in Manitoba. Can. Entomol., 112, 31-42.

BURTON, R. S. AND LEE, B. N. 1994. Nuclear and mitochondrial gene genealogies and allozyme polymorphism across a major phylogeographic break in the copepod Tigriopus californicus. Proc. Natl. Acad. Sci. U.S.A., 91, 5197-5201.

COOK, D. R. 1954a. Preliminary list of the Arrenuri of Michigan Part I. The subgenus Arrenurus. Trans. Am. Microsc. Soc., 73, 39-58.

COOK, D. R. 1954b. Preliminary list of the Arrenuri of Michigan Part II. The subgenus Megaluracarus. Trans. Am. Microsc. Soc., 73, 367-380.

COOK, D. R. 1955. Preliminary list of the Arrenuri of Michigan Part III. The subgenera Micruracarus and Truncaturus. Trans. Am. Microsc. Soc., 74, 60-67.
COOK, w. J. 1991. The Parasitism of Dragonflies by the Water Mite Limnochares americana Lunblad (Acari: Parasitengona: Limnocharadiae). Master's Thesis, University of Guelph.

CORBet, P. S. 1980. Biology of Odonata. Ann. Rev. Ent., 25, 189-217.

Crowell, R. M. 1961. Catalogue of the distribution and ecological relationships of North American Hydracarina. Can. Ent., 93, 321-359.

DANIEL, w. w. 1987. Biostatistics: a Foundation for Analysis in the Health Sciences, 4th edn. Wiley, New York.

EDWARDS, D. D. AND DIMOCK, R. V., JR. 1997. Genetic differentiation between Unionicola formosa and $U$. foili (Acari: Unionicolidae): cryptic species of molluscan symbionts. Invert. Biol., 116, 124-133.

EFFORD, I. E. 1963. The parasitic ecology of some watermites. J. Anim. Ecol., 32, 141-156.

HEBERT, P. D. N. AND BEATON, M. J. 1993. Methodologies for Allozyme Analysis Using Cellulose Acetate Electrophoresis. A Practical Handbook, revised edn. Helena Laboratories, Beaumont, TX.

HEBERT, P. D. N. AND HANN, B. J. 1986. Patterns in the composition of Arctic tundra pond microcrustacean communities. Can. J. Fish. Aquat. Sci., 43, 1416-1425.

HEDGECOCK, D. 1986. Is gene flow from pelagic larval dispersal important in the adaptation and evolution of marine invertebrates? Bull. Mar. Sci., 39, 550-564.

JACKSON, J. K. AND RESH, V. H. 1989. Distribution and abundance of adult aquatic insects in the forest adjacent to a northern California stream. Envir. Entomol., 18, 278283.

JALIL, M. AND MITCHELL, R. 1972. Parasitism of mosquitoes by water mites. J. Med. Entomol., 9, 305-311.

JENSEN, T. AND WASHINO, R. K. 1994. Comparison of recapture patterns of marked and released Aedes vexans and Ae. melanimon (Diptera: Culicidae) in the Sacramento Valley of California. J. Med. Entomol., 31, 607-610.

Johnson, C. G. 1969. Migration and Dispersal of Insects by Flight. Methuen, London.

KARL, S. A. AND AVISE, J. C. 1992. Balancing selection at allozyme loci in oysters: implications from nuclear RFLPs. Science, 256, 100-102.

KOUWETS, F. A. C. AND DAVIDS, C. 1984. The occurrence of chironomid imagines in an area near Utrecht (the Netherlands), and their relations to water mite larvae. Arch. Hydrobiol., 99, 296-317.

LANCIANI, C. A. 1978. Parasitism of Ceratopogonidae (Diptera) by the water mite Tyrellia circularis. Mosquito News, 38, $282-284$.

LESAGE, L. AND HARRISON, A. D. 1980. The biology of Cricotopus (Chironomidae: Orthocladiinae) in an algal-enriched stream: Part II. Effects of parasitism. Arch. Hydrobiologie Supplementband, 58, 1-25.

MANDRAK, N. E. AND CRossman, E. J. 1992. Postglacial dispersal of freshwater fishes into Ontario. Can. J. Zool., 70, 22472259.

MitchelL, R. 1959. Life histories and larval behavior of Arrenurid water-mites parasitizing Odonata. J. NY Entomol. Soc., 67, 5-12. 
MitChell, R. 1962. Storm-induced dispersal in the damselfly Ischnura verticalis (Say). Am. Midl. Nat., 68, 199-202.

MitChell, R. 1965. Host exploration of two closely related water mites. Evolution, 21, 59-75.

MIYAKAWA, K. 1994. Autumnal migration of mature Sympetrum frequens (Selys) in western Kanto Plain, Japan (Anisoptera: Libellulidae). Odonatologica, 23, 125-132.

Mullen, G. R. 1974. The Taxonomy and Bionomics of Aquatic Mites (Acarina: Hydrachnellae) Parasitic on Mosquitoes in North America. Ph.D. Thesis, Cornell University.

MULLEN, G. R. 1976. Water Mites of the Subgenus Truncaturus (Arrenuridae, Arrenurus) in North America. Bull. Cornell Univ. Agr. Exp. Station, Vol. 6, no. 17.

NÜRNBERGER, B. AND HARRISON, R. G. 1995. Spatial population structure in the whirligig beetle Dineutus assimilis: evolutionary inferences based on mitochondrial DNA and field data. Evolution, 49, 266-275.

PALUMBI, S. R. 1995. Using genetics as an indirect estimator of larval dispersal. In: McEdward, L. (ed.) Ecology of Marine Invertebrate Larvae, pp. 369-387. CRC Press, Boca Raton, FL.
SERVICE, M. W. 1993. Mosquito Ecology: Field Sampling Methods, 2nd edn. Elsevier Applied Science, New York.

SLATKIN, M. 1994. Gene flow and population structure. In: Real, L. A. (ed.) Ecological Genetics, pp. 3-17. Princeton University Press, Princeton, NJ.

SMITH, B. P. 1998. Loss of larval parasitism in Parasitengonine mites. Exp. Appl. Acarol., 22, 187-199.

SMITH, I. M. AND COOK, D. R. 1991. Water mites. In: Thorp, J. H. and Covich, A. P. (eds) Ecology and Classification of North American Freshwater Invertebrates, pp. 523-592. Academic Press, New York.

SMITH, I. M. AND OLIVER, D. R. 1986. Review of parasitic associations of larval water mites (Acari: Parasitengona: Hydrachnida) with insect hosts. Can. Ent., 118, 407-472.

STECHMANN, D.-H. 1978. Eiblage, parasitismus und postparasitische entwicklung von Arrenurus-Arten (Hydrachnellae, Acari). Zeit. Parasitenkunde, 57, 169-188.

WAPLES, R. S. 1987. A multispecies approach to the analysis of gene flow in marine shore fishes. Evolution, 41, 385-400.

WEIR, B. S. 1990. Genetic Data Analysis: Methods for Discrete Population Analysis. Sinauer Associates, Sunderland, MA. 